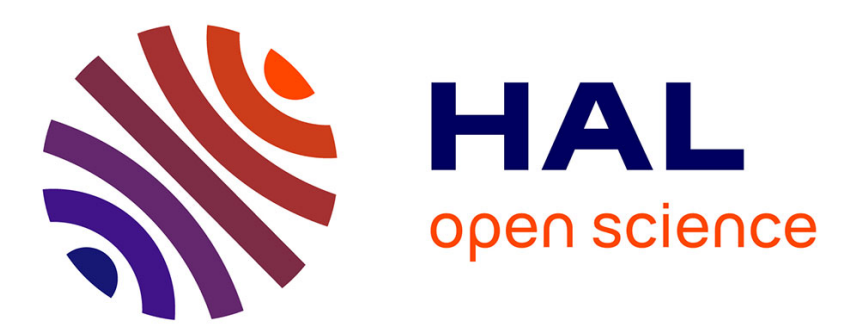

\title{
Research on Construction of Cloud Service Platform of Sci-tech Information for Agricultural Research System
}

Ruixue Zhao, Yuantao Kou, Ruopeng Du, Liangliang Gu, Honglei Yang

\section{To cite this version:}

Ruixue Zhao, Yuantao Kou, Ruopeng Du, Liangliang Gu, Honglei Yang. Research on Construction of Cloud Service Platform of Sci-tech Information for Agricultural Research System. 8th International Conference on Computer and Computing Technologies in Agriculture (CCTA), Sep 2014, Beijing, China. pp.556-564, 10.1007/978-3-319-19620-6_62 . hal-01420271

\section{HAL Id: hal-01420271 \\ https://hal.inria.fr/hal-01420271}

Submitted on 20 Dec 2016

HAL is a multi-disciplinary open access archive for the deposit and dissemination of scientific research documents, whether they are published or not. The documents may come from teaching and research institutions in France or abroad, or from public or private research centers.
L'archive ouverte pluridisciplinaire HAL, est destinée au dépôt et à la diffusion de documents scientifiques de niveau recherche, publiés ou non, émanant des établissements d'enseignement et de recherche français ou étrangers, des laboratoires publics ou privés. 


\title{
Research on Construction of Cloud Service
}

\section{Platform of Sci-tech Information for Agricultural}

\section{Research System}

\author{
Ruixue Zhao ${ }^{1, \mathrm{a}}$, Yuantao Kou ${ }^{1, \mathrm{~b}}$, Ruopeng Du ${ }^{1, \mathrm{c}}$, Liangliang $\mathrm{Gu}^{1, \mathrm{~d}}$, Honglei Yang ${ }^{1, \mathrm{e}}$ \\ ${ }^{1}$ Agricultural Information Institute, Chinese Academy of Agricultural Sciences,Beijing \\ 100081, China \\ azhaoruixue@caas.cn, ${ }^{\text {b }}$ kouyuantao@caas.cn, ${ }^{c}$ duruopeng@caas.cn, ${ }^{d}$ guliangliang@caas.cn, \\ e363137894@qq.com
}

\begin{abstract}
In this paper, an overall architecture and service model of cloud service platform of sci-tech information based on cloud computing for agricultural research system were proposed, aiming at promoting the co-construction and sharing among information service institutions in agricultural research system. The platform will integrate resources and services of co-construction institutions into a shared body, and form a new science and technology information service system to provide network infrastructure, resources, platform and various application services for agricultural research system. And through dynamic management and distribution of a variety of services, it will meet the needs of users at different levels, such as institutions, academic teams and individuals and so on.
\end{abstract}

Keywords: agricultural research system; science and technology information; cloud service; cloud computing; digital library

\section{Introduction}

Cloud computing is a new calculation model developed on the basis of distributed computing, parallel processing and grid computing and so on. Its core is to provide mass data storage and network computing services. Based on cloud computing, cloud service is a new IT service delivery model, aiming to combining technology and 
business delivery for the users [1]. Cloud is the center of the data storage and application service.

The emerging of cloud computing services has attracted more attention from various areas in the world. Google, IBM, Amazon, Microsoft and other IT giants have launched their own cloud initiative [1]. In the field of library and information, OCLC (Online Computer Library Center) launched the first cloud-based collaborative Web-level library management services [3][4]. In China, CALIS (China Academy Library and Information System) has carried out the development strategy of CALIS cloud computing at the earlier time, as well as research and exploration of cloud service platform of digital library [5].

Regarding scientific research information service system (library) as research object, this paper focused on the application of cloud computing in resources construction and services of agricultural research system.

\section{Significance of Construction}

Chinese agricultural research system contains three components, including independent agricultural research institutions of government, agricultural and forestry colleges and universities, and research institutes of private sector. In this paper, the scientific research system (ARS) consists of the Chinese Academy of Agricultural Sciences (CAAS), Chinese Academy of Fishery Sciences, Chinese Academy of Tropical Agriculture Sciences and the provincial academies of agricultural sciences. These institutions have a number of relatively independent professional institutes, and undertake tasks of agricultural science and technology innovation and industrial development. Meanwhile, these academies of sciences have specialized information service unit (library) which undertake research resources construction and information services of the internal system. For example, CAAS, a national comprehensive agricultural research institution, has 38 professional research institutes (centers) distributed throughout the country, one graduate school and a number of major national science and engineering projects, State Key Laboratory, Key Laboratory of the Ministry of Agriculture and Field Scientific Observation Station. For a long time, the Library of CAAS (National Agricultural Library) has undertaken important tasks of providing supporting scientific literature and information services for CAAS and the whole nation. 
With the rapid development of internet and other modern information technology, and the increased pressure of agricultural science and technology self-dependent innovation in China, the requirements of information and services of agricultural research system are undergoing significant changes. Firstly, with the rapid development of the internet and a number of commercial information institutions, more pathways are provided to access information for researchers. The needs of researchers for information services provided by Library have gradually been weaken. Secondly, the demand for science and technology information of scientific research personnel is more urgent. In particular, they need to keep abreast of the latest research developments of disciplines and peers progress both at home and abroad. The needs of information content are also charactered by timeliness, specialty, comprehensiveness, dynamics and knowledge. The third change is that the way of access to information is featured with digitization, networking, and mobility. The network of scientific communication and collaboration environment become the mainstream of modern scientific research. The forth one is that researchers need more information finding ways and various information processing tools. They pay more attention to the preservation, sharing and utilization of the academic achievements.

Due to these changes, the library and other specialized information service organization have faced serious challenges. Because of lack of funding, manpower, knowledge, basic conditions and others, single information agency increasingly highlights limitations in conducting resource construction and providing services. Obviously, there need union, co-building, sharing and co-prosperity. What comes first is infrastructure construction. The infrastructure is weak in some Libraries of the academy system or information agency, and the capacity to update and maintain is inadequate. These affect the quality of the information service. But there are also some individual information services which have obvious advantages of the resources, technology, personnel, and equipment as well. The second issue is resource sharing. Although the academies of agricultural research system like CAAS have accumulated a certain amount of information resources for a long time via various channels, including the purchased electronic resources and self-built specialized databases, which played an important role in the service, it is still unable to meet the expanding needs of scientific users. And for a long time, the resource construction and service capacity are quite different and collaborative sharing is weaker among the various information institutions of agricultural research system. These lead to coexist of repeated construction and inadequate resources. That not only is very wasteful, but 
also affects the overall effect of service. Thirdly, there are also a lot of same subjects, although the academies of agricultural research system have their own unique fields of study. It is more prominent for the role of joint construction of information resources and providing service for researchers with similar research direction, although they are distributed in different research institutions.

Cloud computing technology provides an effective means to solve these problems. It opened up a new train of thought (library) of the co-construction and sharing for promoting information service organization (library) of agricultural research system in China. In this context, based on cloud computing, we proposed the construction of cloud service platform of agricultural scientific research system. Its significances lie in as follows:

(1) To promote the development of resource construction and service alliance of agricultural research system in China, to co-build a new system for agricultural research service system, achieve value adding and extension under limited conditions of resources, systems, services, technology etc.. It can provide broader and more convenient service for scientific users, and reduce a lot of problems such as scattered resources, self-limited service system, disorders of multi-service gateway when accessing system, and so on.

(2) To reduce duplication of construction through integration of high-quality resources of agricultural research system, and alleviating resources construction and service limitations of the individual information service institution especially due to lack of technology, talent, capital, ,to improve overall resources support ability and service level of agricultural research system.

(3) To adapt with the changing environment. With the popularization of internet services, it is supposed to take the advantages of professional information services, focusing on the construction of characteristic resources of agricultural subject, which are scarce on the Internet, expanding specialized knowledge services. And the private cloud or hybrid cloud service platform of sci-tech information for agricultural research system can be built when enjoying the services of internet public cloud, to improve competitiveness of agricultural specialized information service organization. 


\section{Construction Infrastructure}

The construction of the proposed platform not only needs infrastructures such as good network environment, High-Performance Server, storage equipment, but also calls for rich agricultural professional data resources and service applications along with co-construction and sharing mechanism and strong desire in the system. As a result, we should fully consider the existing resources and conduct the optimized integration and promotion.

First of all, CAAS has provided a good network information environment, and established the first agricultural science and technology information network in China. The library of CAAS, also the agricultural Library of NSTL, takes responsibility of construction of the strategic guarantee system of national agricultural science and technology literature resource. It plays a crucial and pivotal role in the national agricultural specialized library and intelligence system. In 2005, the National Agricultural Library hosted and established the "National Agricultural Science and Technology Literature Information and Service System (NAIS)[6]" which has achieved effective integration and service integration of multi-source, distributed, and heterogeneous resources and provided "one-stop" information service of science and technology to the whole country.

Secondly, CAAS established the largest National Agricultural Scientific Data Sharing Center (Agridata)[7] in China with collaboration of Chinese Academy of Fishery Sciences, Chinese Academy of Tropical Agriculture Sciences, and some of the provincial academies of agricultural sciences, under the support of the National Science and Technology Basic Condition Platform Program. It is a national scientific data resource sharing and service system, which consists of a main center, seven sub-centers, and 15 provincial sharing services branches.

Thirdly, the information service institutions (library) of agricultural research system established the "Electronic Resources and Services Union of Agricultural Scientific Research system (Agricultural science union)" according to the initiative of library of CAAS, which collectively carries out group purchase and resource sharing. By now the Union has more than 30 member institutions (libraries).

Fourthly, in order to adapt to the new requirements of open scientific research information environment and scientific research innovation, the library of CAAS has built a technology system and a support platform for large-scale digital resource processing and distributed heterogeneous resources integrating based on the "cloud 
sever" open architecture since 2010. Meanwhile it has built a comprehensive agricultural scientific digital knowledge warehouse containing agricultural science and technology literature, scientific data, open access resources and other third-party Internet resources. CAAS Library also established a multi-level service system based on NAIS public and popular service and offers personalized services to areas, organizations, teams, subjects, and personal. A series of achievements has been achieved on resources construction and personalized technology, tools and platform service. These results have been preliminarily applied in CAAS institutes, academic teams and several provincial agricultural information service academies such as Beijing, Shanxi, Sichuan, Xinjiang and Tibet Academy of Agricultural Sciences. In this context, the prototype of cloud service platform of agricultural research system has formed.

\section{Platform Overall Architecture}

The proposed platform is a digital research information platform based on a variety of technologies and services, which provides diversified services for service institutions, research institutions, scientific researchers and even agricultural scientific and technological personnel all over the country. The overall architecture of the platform is shown in the Fig. 1. The platform adopts the open system architecture based on "cloud services", with support of the CAAS network infrastructure and the scientific research resources guarantee system. It integrates and uses other resources and services of agricultural research system, as well as external information environment of scientific research.

Cloud service center has a long-term, basic, stable resource and service support from NAIS, Agridata, NSTL, other agricultural research institutes, the Internet open access system, and third-party system. Among them, NAIS mainly focuses on literature construction and service, while Agridata aims at integration and sharing of scientific data. By integrating and reorganizing these sources, as well as encapsulating and clouding the core function modules of these service system, cloud service center builds a series of cloud service components with both versatility and reusability, including resources, tools, systems, Open APIs, and Web Services. It provides services for cloud users, such as professional information service agencies, research institutions, academic teams, individual users and third-party users, etc. As the 
resource and service center of agricultural research system, cloud service center can harvest resources shared by various users, thus forming a shared knowledge base of national agricultural research. Meanwhile, it is responsible for global resource storage, organization, management, distribution and scheduling, conducting service monitoring and service statistics, maintaining login accounts and user rights, deploying various kinds of application service, and securing the safety of resource and service, etc. A resource sharing and collaborative service model can be formed through cloud service center, a public service portal of information institution and a personalized knowledge service platform for organizations, groups, individuals, disciplines and projects, which will enhance the overall service ability of agricultural research system.

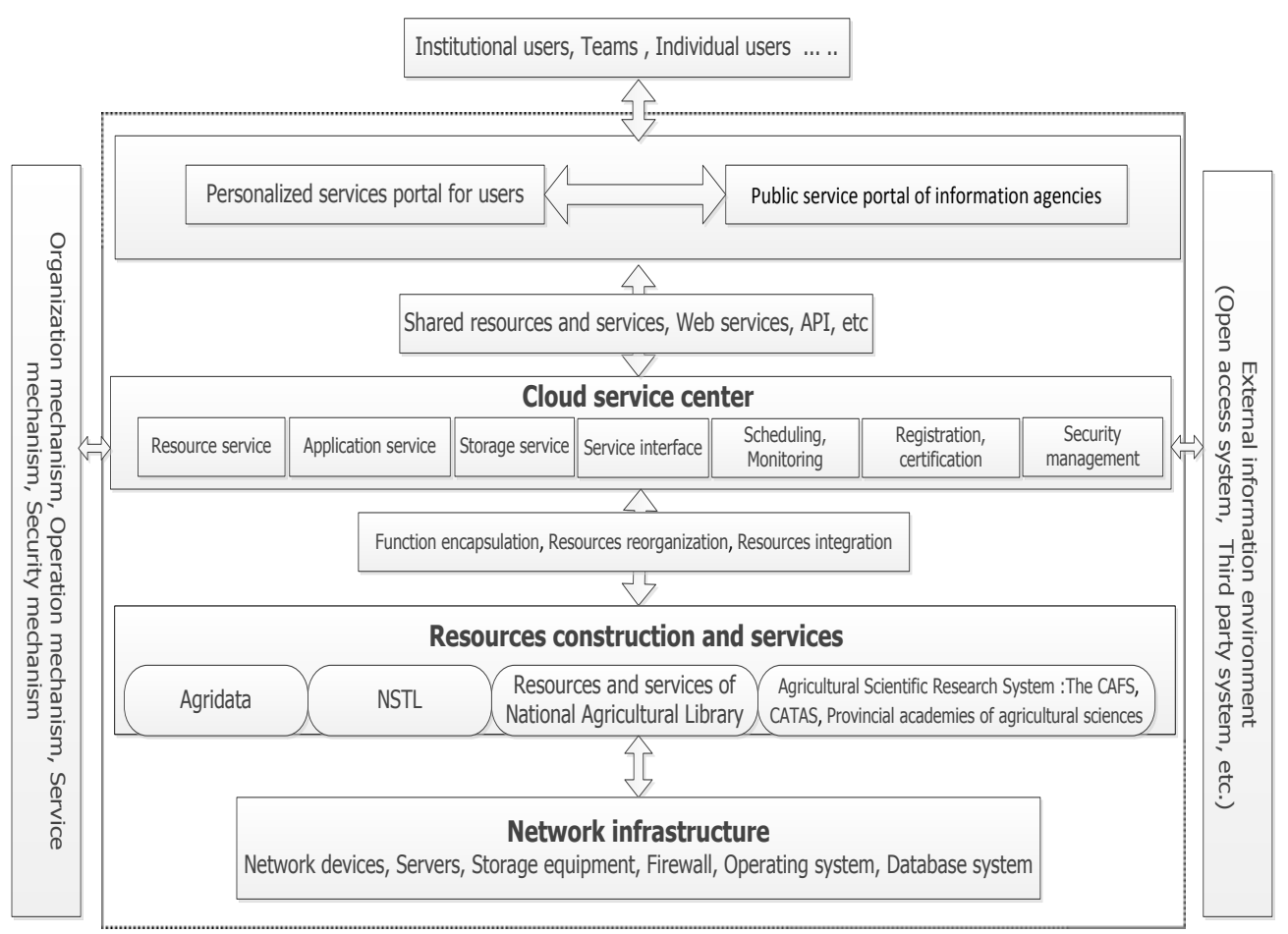

Fig. 1. Overall architecture of the platform

\section{Cloud Service Model}

The platform is composed of a series of services, which can be divided into 5 
layers as shown in the Fig.2. The 5 layers are infrastructure layer, platform service layer, application service layer, cloud service layer and cloud clients, respectively [8-12].

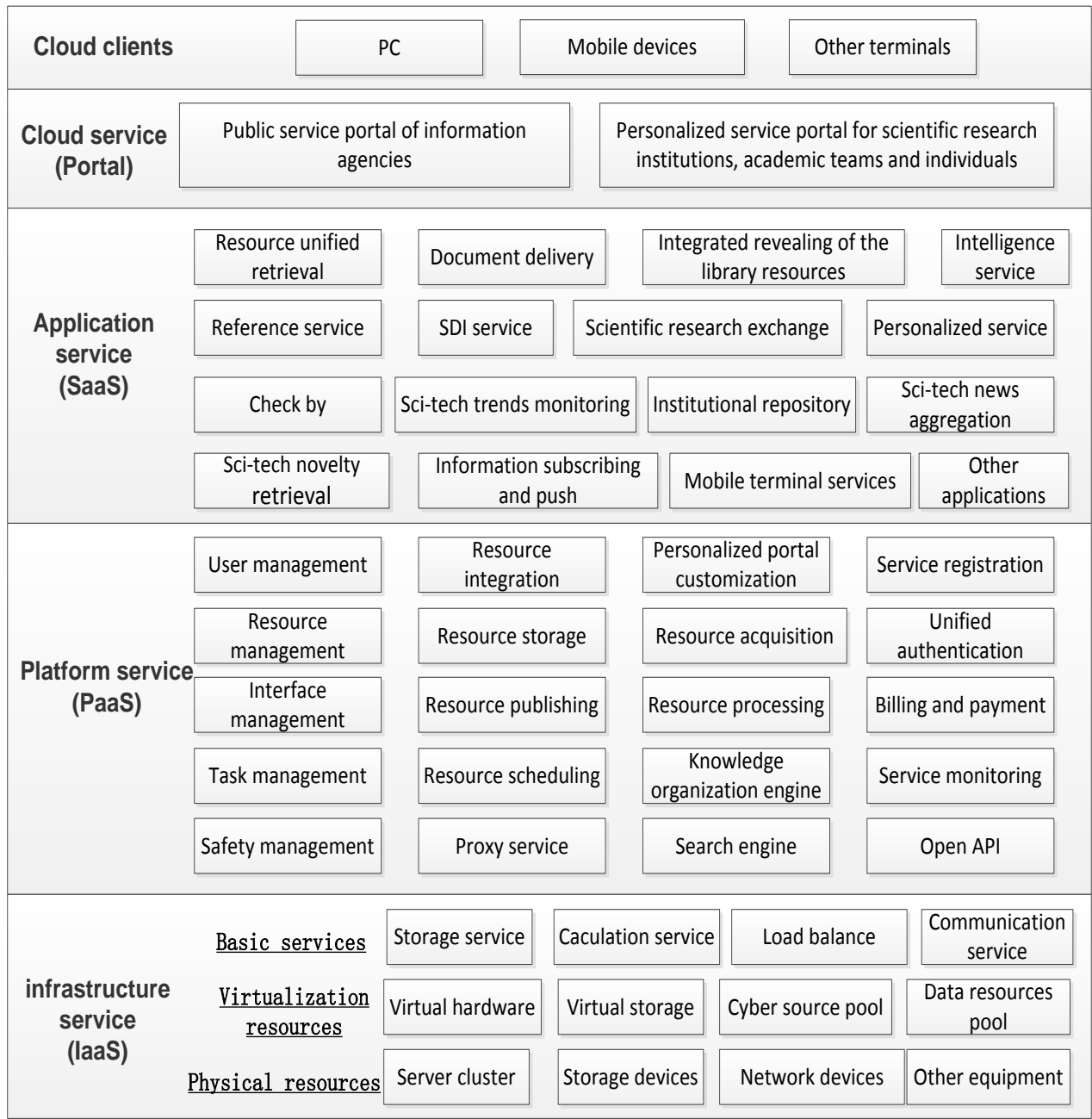

Fig. 2. Cloud service model 


\subsection{Infrastructure layer (IaaS)}

The infrastructure layer (IaaS) at the bottom is assembling of virtualized hardware resources and related management functions. It is the basis of the whole structure of cloud service platform, providing hardware, network and resource sharing service for the users of agricultural research system. It mainly includes three parts: 1) the physical resources which is composed of network devices, servers, storage devices and other equipment; 2) the virtualization resources which contains virtual server cluster, virtual storage, cyber source pool, data resources pool; 3) the basic management services based on virtual resources such as storage service, calculation service, communication service and load balance. The infrastructure cloud services can not only make full use of superior server resources, cyber source and storage resources within the system, but also decrease the idle resources, avoiding repeated purchase of hardware resources, and reducing the burden of weak institutions in the construction of hardware resources.

\subsection{Platform service layer (PaaS)}

The platform service layer (PaaS) is a collection of software resources with generality and reusability, mainly including the basic and core services such as resource acquisition, processing, storage, organization, management, publishing, searching, sharing and use, which can provide direct service for users at all levels, and also services through Open API. The PaaS service provides services to support the professional information service organization and users to create local personalized service system of their own, which to a certain extent solved the problem of lacking technology in network information service of the institutions.

\subsection{Application service layer}

The application service layer (SaaS) is to provide the end user with interface and application services. It mainly includes: resource retrieval, cataloging, document delivery, reference, SDI service, sci-tech trend monitoring, institutional repository, sci-tech novelty retrieval, intelligence service and the deep-seated personalized knowledge services aimed at scientific research institutions, academic team and 
individual users, such as knowledge management, knowledge map, knowledge navigation, and knowledge association.

\subsection{Cloud service layer}

The Cloud service layer is a service interface for users at all levels, mainly through the professional information service portal (including public service portal of information agencies and personalized service portal for scientific research institutions, academic teams and individuals). The gateway construction can use the IaaS, PaaS, SaaS and other services that the platform provides, including various forms of data, tools, equipment, and systems. However, the permissions different users have when accessing the resource and services are different.

\subsection{Cloud clients}

The cloud clients are the main terminals with which users have access to the service portal and use the resources and services.

\section{Service Mode}

This platform can offer flexible, dynamic service configuration and service delivery according to users' needs. Considering permission to access, intellectual property and services and other factors, the Cloud service platform provides different services such as paid services, free services, and adjustment access by scenario sensitive.

The information service institutions of agricultural research system provide following services:

(1) The platform tools are provided which support the information service institutions to establish local personalized service portal. Those institutions will no longer need to build and develop their own information software. They only need access the needed services according to their business demands in accordance with the contract. This is the way to implement co-construction and sharing between application service systems and information services.

(2) The platform can offer service interface. Information service institutions can use directly according to the service authorization. Those service interfaces allow 
sub-sites access to the resource and service offered by cloud service platform. It enhances the convenience of access to resources by embedded services in the user local information environment. The general features include integrated retrieval, knowledge navigation, SDI service, reference, etc.

(3) Cooperative service platform provides services such as group purchase of electronic resources, joint cataloging, joint processing, institutional repository alliance, collaborative research, document delivery, interlibrary loan etc. Co-construction units can formulate powerful resource and service superiority based on unified standards and specifications, as well as mutual coordination.

For professional research institutes, academic teams and individual users, the available services include:

(1) Users can build their own personalized service portal with cloud services. They can also embed required services into their local information environment through the embedded interface.

(2) Users can access to the resources and services of cloud service platform directly through the terminal access. The service in the agricultural research system is more comprehensive, individualized and integrated under the environment of cloud service system.

\section{Conclusion}

Undoubtedly, Cloud Computing brings unprecedented challenges and chances to the information service industry. The cloud service platform of agricultural research system presented in this paper will promote the resources construction and the development of sharing services union among information service institutions, and improve the overall information service of agricultural research system. However, there are still some problems to be solved. They include the issues of cloud computing security, resources copyright and ideas identification, how to reach an agreement about coalition building between agricultural research systems, and how to establish an efficient and mutually beneficial pattern effectively integrating the technologies, resources, services of member institutions. In short, in the global open information environment, the alliance of professional information institutions not only contribute to their development, but also facilitate more progress of agricultural sci-tech information service industry, with the continuous competition of the business 
information agencies, publishers, and under the condition of limited resources,. Moreover, it is beneficial to the broad masses of agricultural science and technology innovation and industrial development.

\section{References}

1. YU Xin,WANG Jing-yi. Research on the Cloud Services Platform Architecture of Digital Library Based on Cloud Computing Technology. Information Science [J], 2012, 30(12):1854-1857(in Chinese).

2. Guo JinTing. Studying on the model of library cloud service under computing environment[D]. 2012, 5(in Chinese).

3. Zhang Wenhua, Feng Kai, Hu Guangling, Hu Chun. Cloud Computing and Its Application and Obstacles in Library. Liabrby and information service. [J], 2010, 54(7):42-45(in Chinese).

4. Products \& Services. [EB/OL]. (January 23, 2014) . http://www.oclc.org/en-asiapacific/services.html.

5. Zhang Baiying. Theory and Practice of Socialization of University Library Information Service-Library of Guangzhou University as an Example. Journal of Academic Libraries[J], 2009, (4):13-18(in Chinese).

6. National Agricultural Science and Technology Literature Information and Service System (NAIS). [EB/OL]. (January 23, 2014) . http://www.nais.net.cn(in Chinese).

7. National Agricultural Scientific Data Sharing Center (Agridata). [EB/OL]. (January 23, 2014) . http://www.agidata.cn(in Chinese).

8. Chen Chen, Han Jincang. Improved Resource Management and Application Platform for Digital Library under Cloud Computing Environment. Journal of Modern Information[J], 2013, 33(2):18-20(in Chinese).

9. Xie Yuan, Zhang Jingpeng, Zhou Xiu-xia. Design and Implementation of Cloud Computing Services Platform in Library Consortium. Information Science[J], 2012, 30(12):1854-1857(in Chinese).

10. Yang Fang, Dai Lei. Construction on Regional Digital Library Alliance Based on Cloud Services. Journal of Foshan University(Social Science Edition) [J], 2013, 31(4):87-91(in Chinese).

11. Wang Xiaonan. Research on Regional Digital Library Based on Cloud Computing. Digital Library Forum[J] , 2010,(11):63-70(in Chinese). 
12. Wu Zhiqiang, Xu Ge. Discussion about the system of library consortia based on the cloud service. new century library[J], 2011,(3):8-10(in Chinese). 